\title{
EARTHQUAKE RESISTANT DESIGN OF STRUCTURES IN MEXICO
}

\author{
Enrique del Valle Calderón \\ Camelias No. 16 Col. San Agustín \\ 01060, México D.F. México
}

\begin{abstract}
A critical review of Mexico City seismic codes proposed from 1942 to 1987 is performed. The practical aspects of the codes are discussed, in particular the ones related to its 1987 version. The possibility of increasing the ordinates of the design spectra for the so-called soft-soil zone of Mexico City is analysed, this based an past and recent earthquake observations.
\end{abstract}

\section{RESUMEN}

Se hace una revisión crítica de los aspectos sísmicos de los reglamentos de construcción propuesto para la Ciudad de México desde 1942 hasta 1987. Los aspectos prácticos de los mencionados reglamentos son discutidos, en particular los relacionados con el reglamento de 1987 . Se analiza la posibilidad de incrementar las ordenadas del espectro de diseño para la zona de suelos blandos de la Ciudad de México, lo anterior basado en observaciones de temblores pasados y recientes.

\section{INTRODUCTION}

Earthquake resistant design in Mexico is closely related to the practice in Mexico city. Although each State of the Republic is independent in code aspects, the ones that have a Code, follow the Federal District model. In earthquake matters, a seismic zonation of the country recognizes four zones of intensity, fig 1 . The strongest earthquakes occur along the Pacific Coast, on the states of Chiapas, Oaxaca, Guerrero, Michoacan, Colima and Jalisco. Baja California and Sonora are also affected by the earthquakes produced along San Andreas fault.

Some recommendations without official recognition have been published by the Federal Comission of Electricity; they cover the whole country on seismic aspects.

After the 1985 earthquake a strong effort was made to elaborate actualized codes for each state of the country. As a result, several states have now their own actualized code, as the State of Guerrero, for instance.

Several codes have been published for the Federal District in recent years. In two occasions, 1957 and 1985, modifications have been made due to the strong effects of seismic events.

The Code of the Federal District is a Presidential Decree and has to be published in the "Official Diary". Its evolution in recent years has been largely influenced by the research done at the Institute of Engineering of the National Autonomous University of Mexico, under the leadership of E. Rosenblueth.

* Trabajo invitado a la 61 st Anual Convention de la Structural Engineers Association of California (SEAOC) celebrada en Ixtapa, Gro. del 30 de septiembre al 2 de octubre de 1992. 


\section{EVOLUTION OF THE FEDERAL DISTRICT CONSTRUCTION CODE ON SEISMIC ASPECTS}

Code evolution regarding seismic design has almost always been caused by important seismic events which discover the defficiencies present in current documents. Several such changes have ocurred in Mexico in the last decades, table 1.

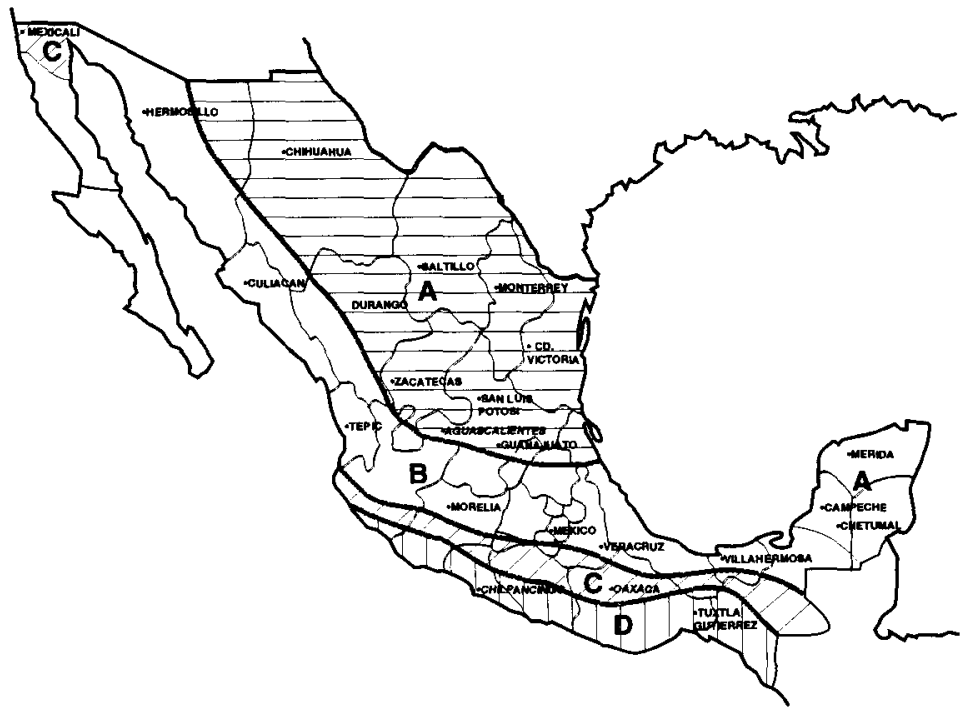

Fig. 1 Seismic Zoning in Mexico

Table 1. Different codes for Mexico city in recent years.

Date of Publication

July 23, 1942

September 18, 1957

February 9,1966

December 14, 1976

October 18,1985

July 3, 1987
Name

Reglamento de las Construcciones y de los Servicios Urbanos en el D.F.

Modifications due to the July 28, 1957 earthquake.

Reglamento de Construcciones para el D.F., Cap. XXXI.

Reglamento de Construcciones para el D.F., Título IV.

Modifications due to the Septiember 19, 1985 earthquake.

Reglamento de construcciones para el Distrito Federal.

(Note: On august 2, 1993 a new code was approved, ref. 10)

When the July 28, 1957 earthquake ocurred, the Code in practice, ref 1 , was obsolete on seismic matters; many engineers recognized this obsolescence and preferred to use either San Francisco or Los Angeles recommendations. The 1942 code replaced another one published in 1920; it was very limited on earthquake aspects.

Maximum height of buildings according to the 1942 Code was limited to 35 meters. Constructions were classified into eight different types in function of its importance and destiny, from the ones which should remain undamaged in any event, as energy plants or water deposits and pumping stations, to constructions with negligible importance whose failure would not damage persons or other structures. Seismic coefficient was constant with height and varied according to the type of structure from $0.10 \mathrm{~g}$ to zero. There was no recognition of differences in soil response. For ordinary buildings the coefficient was $0.025 \mathrm{~g}$. Allowable stresses in concrete or steel structures were increased $33 \%$ for the combined effects of vertical and horizontal loads. 
Earthquake designs were required for buildings exceeding $16 \mathrm{~m}$ in height or twice the minimum dimension of its plan layout.

After the 1957 quake, "Emergency Regulations" were published, ref. 2. This 7.5 magnitude event with epicenter in Guerrero, caused several collapses and damaged many buildings located on the zone of soft soil of Mexico city.

Seismic coefficients were greatly increased, especially for the soft soil sites; however, these Norms recognized different response of the structures according to the soil on which they were founded as well as to the type of structure used or the importance of the construction.

Three types of soil were considered: soft soils with very compressible clay layers exceeding $10 \mathrm{~m}$ in depth, transition soils for clay formations of medium to low compressibility interbedded with sand or silt layers, with total depth less than $10 \mathrm{~m}$ and firm soils, with materials of high bearing capacity and low compressibility.

Three types of structural layouts were considered: 1 , steel or concrete structures with masonry filling walls contributing to the stiffness; 2 , steel or concrete skeletal structures, without other elements contributing to stiffness and 3 , load bearing wall structures.

The following table illustrates the seismic coefficients proposed to obtain base shears. To estimate forces in upper levels a linear distribution of accelerations was considered in such a way that the relation of the shear to the total weight at the base, was equal to the specified seismic coefficient.

Table 2. Seismic Coefficients, 1957 Emergency Regulations

\begin{tabular}{lcccc}
\hline Group of importance & Type of structure & Soft & Type of soil & Transition \\
A & 1 & 0.15 & 0.13 & Firm \\
(very important buildings) & 2 & 0.20 & 0.18 & 0.12 \\
& 3 & 0.15 & 0.18 & 0.20 \\
\hline B & 1 & 0.07 & 0.06 & 0.05 \\
(normal buildings) & 2 & 0.10 & 0.09 & 0.07 \\
& 3 & 0.07 & 0.09 & 0.10 \\
\hline C & 1 & & & \\
(unimportant buildings) & 2 & 0 & 0 & 0
\end{tabular}

Apparently the seismic coefficient for normal buildings in soft soils was four times greater than that of the previous code; however, the increase in seismic coefficients was combined with an increase in allowable stresses for the effects of vertical and earthquake loads. For the case of concrete structures, allowable stresses in the concrete were twice those corresponding for vertical loads alone (excepting diagonal tension, which was increased only $33 \%$ ); in reinforcing steel allowable stresses were increased to $90 \%$ of yield stresses or to $80 \%$ of the apparent elastic limit for special steels. In the case of steel structures the increases in allowable stresses were $67 \%$.

Limit design analysis was also permitted with very low safety factors: 1.1 in flexure or 1.3 for axial loads for steel structures and 1.2 or 1.5 for reinforced concrete structures.

Horizontal displacements were restricted to 0.002 times the difference in height of the levels, excepting industrial buildings. Torsional provisions were also included in the norms. 
The Emergency Regulations of 1957 were the basis of the 1966 code. In fact this code was ready for publicacion in 1960 but different reasons delayed its appearance.

In the 1966 Code, ref 3, transition soils were incorporated to the soft ones, leaving only soft or firm soils to be considered.

Some modifications were made in the three groups of buildings arranged by type of occupancy, especially the definitions for group $\mathrm{A}$ or very important buildings, that included hospital and other buildings with surface larger that $400 \mathrm{~m}^{2}$, where frequent gathering of people is possible, as schools, stadiums, cinemas, churches, bus or train stations or similar.

Classification according to structural type was also modified. The first group included skeletal structures deforming by flexure of structural elements; the second group included bearing wall structures and the third one was for special structures (inverted pendulums) like elevanted tanks, or chimneys.

Base shear coefficients for group B structures (normal buildings) were as follows:

TYPE OF STRUCTURE

1

2

3
TYPE OF SOIL

SOFT FIRM

$\begin{array}{ll}0.06 & 0.04\end{array}$

$0.08 \quad 0.08$

$0.15 \quad 0.10$

The values should be multiplied by 1.3 for group A structures. Group C structures were not required to be designed for earthquakes loads.

For the combination of vertical and earthquake loads, allowable stresses could be increased $50 \%$ for wood and structural or reinforcing steel; masonry or concrete stresses could be increased only $33 \%$.

For seismic analysis three methods were permitted: a simplified static one for load bearing wall structures of one or two stories in height, provided they satisfied a series of additional requirements. In this method it was only necessary to check the shear strength of the walls against the acting shear forces.

If the structure was more that two stories tall or it did not satisfied the additional requirements, a full static method was enforced, where shear forces and overturning and torsional effects had to be taken into account, as well as lateral displacements including torsional effects.

Inertia forces should be calculated using the expression

\section{$\mathrm{Fi}=\mathrm{CW}(\mathrm{Wihi} /$ Sum Wihi $)$}

Where $\mathrm{C}$ is the seismic coefficient, $\mathrm{W}$ is the total weight of the structure, including reduced live loads; $\mathrm{Wi}$, the weight of each level and hi its height with respect to the base. Shear forces were the sum of inertia forces from top to bottom.

For the calculation of torsional effects, calculated eccentricities between mass and stiffness centers at each level should be increased $50 \%$ and an accidental eccentricity of $5 \%$ of the maximum dimension of the plan, perpendicular to the direction of analysis, should be added.

Earthquake forces could be also calculated using dynamic modal analysis. Design spectra for compressible or firm soils were specified (fig. 2). However, design forces could not be smaller than $60 \%$ of those obtained using the static method.

Overturning moments and torsional effects were computed as for the static method.

Relative displacements were restricted to 0.002 times the difference in elevations but if the non-structural elements were attached to the structure in such a way as to avoid its damage, relative displacements for group A type of buildings were increased to $0.003 \mathrm{~h}$ in the soft soils or $0.004 \mathrm{~h}$ in the firm soils, and no limitations were imposed on group B (normal buildings). 
There were specifications relative to separations between adjacent buildings, with a minimum of $5 \mathrm{~cm}$ or the computed displacement plus $0.006 \mathrm{H}$ in the zone of soft soil or $0.004 \mathrm{H}$ in the firm soil zone, where $\mathrm{H}$ is the height above street level.

An interesting specification about installation of deformimeters or oscilographs for buildings exceeding $45 \mathrm{~m}$ in height or $10,000 \mathrm{~m}^{2}$ in covered surface was included. Unfortunately it was not followed by owners, nor enforced by authorities.

The 1966 Code was modified in 1976 without any special seismic event occurring. The 1976 Code, ref 4 , had important modifications in the form and in the contents.

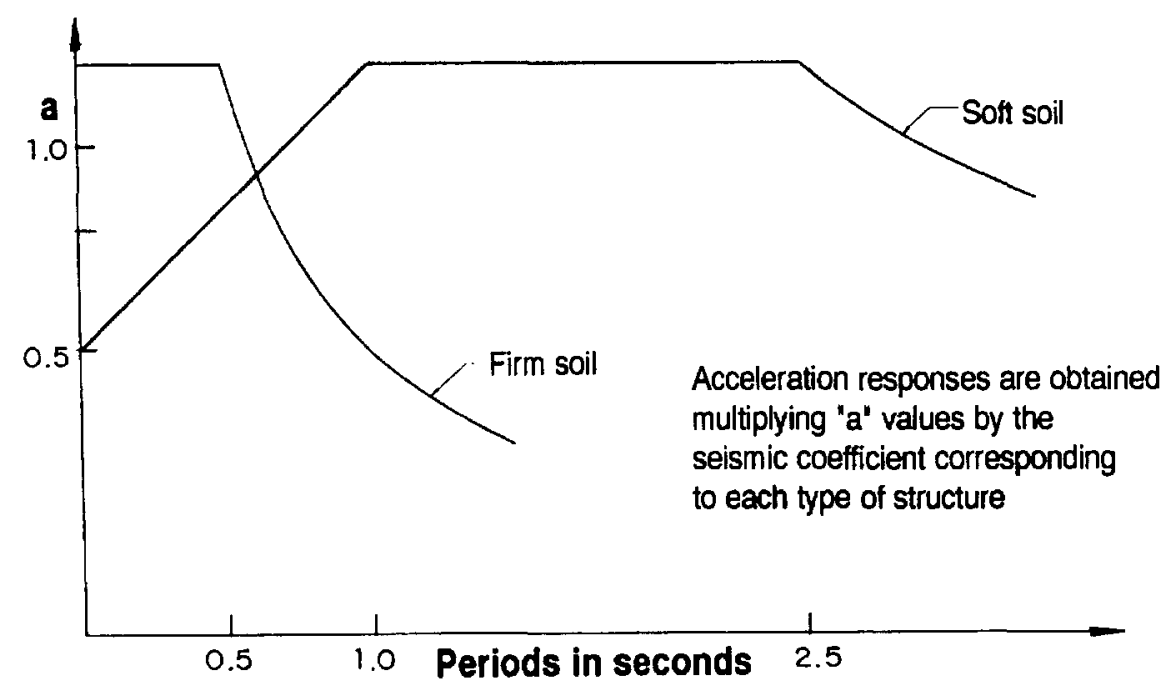

Fig. 2 Design Spectra 1966 Code

With respect to the form of the Code, it consisted in two different types of documents: the code itself and a series of Technical Complimentary Norms with the same enforcement. The Complimentary Norms were for the different materials to be used: Reinforced Concrete, Metallic, Masonry, or Wood Structures, but there were also Complimentary Norms for Foundations and for Wind Effects. Earthquake specifications remained in the Code but had several modifications.

This change in the form was made in order to have more flexibility for future modifications, as Complimentary Norms were not a Presidential Decree; they were released by the Major of the city, who is appointed by the President.

In the 1976 Code, the Federal District soils were again classified in three different types: soft, transition and firm, but with thicknesses of clay layers of $20 \mathrm{~m}$ or more for the first case, varying between 3 and $20 \mathrm{~m}$ for the second case and being less or equal to $3 \mathrm{~m}$ for the firm case. Apparently very high seismic coefficients of $0.24 \mathrm{~g}, 0.20 \mathrm{~g}$ or $0.16 \mathrm{~g}$, respectively, were specified for group B buildings, but they could be reduced in terms of the expected ductility of the structure. This reduction depended on the materials employed, the type of structural layout and on the detailing of structural elements and connections. Ductility reduction factors specified were 1.5 for hollow brick or block walls; 2 , for solid brick walls; 4 , for skeletal structures and a maximum of 6 for reinforced concrete or steel specially designed ductile frames. Seismic coefficients were increased $30 \%$ for important buildings (Group A).

In practice, few engineers used the 6 value, as there were too many details to satisfy and the design of a structure was complicated; the most common used value was 4 , thus obtaining the same basic coefficient of 0.06 for normal buildings on soft soil, as specified in the previous Code; however, it is worth to mention that if partition or facade walls 
were considered "non structural" but were not well isolated to allow displacements of the structure, the reduction factor to use should be 2 or 1.5 , instead of 4 .

The results of structural analysis neglecting those walls are completely different to the ones considering the strength and stiffness of such walls. Failure to recognize this produced a lot of cracks in medium earthquakes, like the one that affected Mexico city in March 14, 1979, ref 5.

It is considered necessary to detail clearly the way in which "non-structural" walls should be attached to the structure in order to satisfy design assumptions and perform "realistic" analyses.

Another important change between the 1966 and 1976 Codes was related to the calculation of lateral displacements, as in 1976 it was not possible to reduce seismic forces for this calculations, thus obtaining values 4 or more times greater than with the 1966 code.

Allowable lateral displacements were increased in the same proportion as the seismic coefficients, with values of $0.008 \mathrm{~h}$ if there were non structural walls that could be damaged or $0.016 \mathrm{~h}$ if special care was taken to avoid this damage. Unfortunately, in many cases this was not understood by practicing engineers.

This situation was fully exposed in the 1985 earthquake, when in many cases pounding occurred between adjacent buildings due to insufficient separation as well as damage to "non structural" walls by the same reason.

Torsional effects were also increased in the 1976 code as accidental eccentricity was doubled, from 0.05 times the maximum dimension of the plan perpendicular to the direction of analysis, to 0.10 of such dimension.

Three types of methods were specified to obtain seismic effects, as before.

The simplified static method was similar to the 1966 Code but in 1976 reduced values of the seismic coefficients for this analysis were given, depending on the height of the structure (maximum was $13 \mathrm{~m}$ ) and type or materials used in the load bearing walls, either hollow bricks or blocks or solid pieces. It was only necessary to verify that the strenght in shear of the walls for each direction of analyses was sufficient, neglecting overturning and torsional effects as well as lateral deformations.

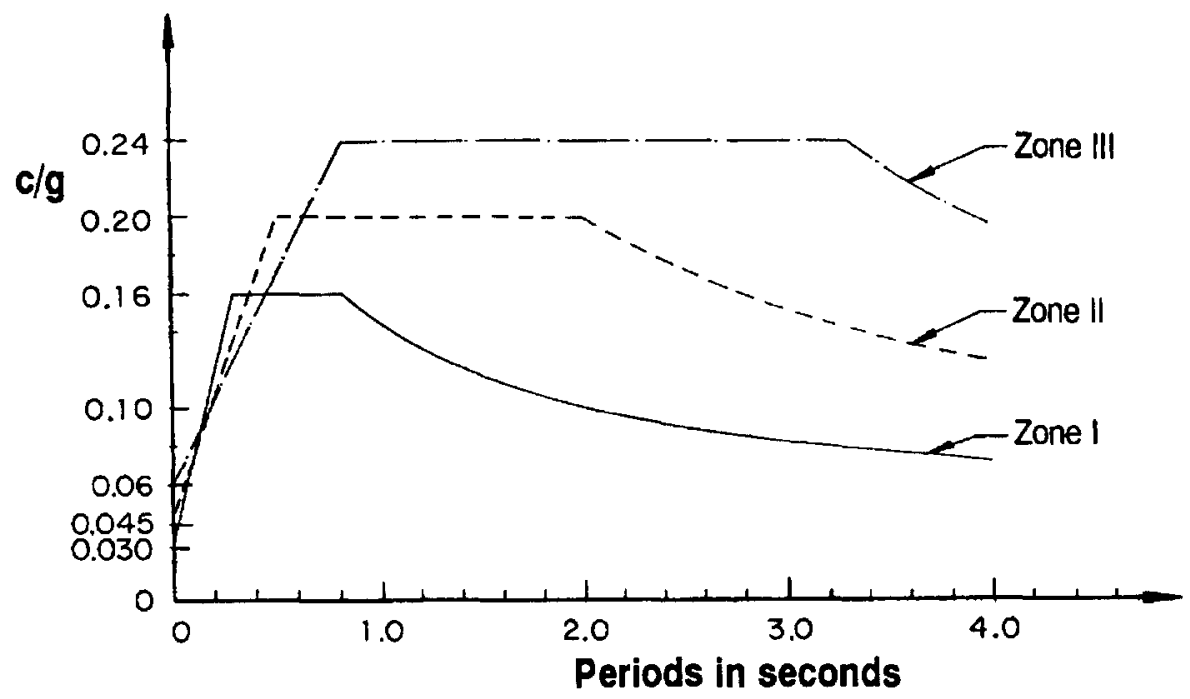

Fig. 3 Design Spectra 1976 Code

The static method, considering lateral deformations and overturning and torsional effects, was restricted for buildings under $60 \mathrm{~m}$ in height. (around 20 stories). 
Earthquake forces, overturning moments and torsional effects were computed as in the previous Code, but with the modification in eccentricity already mentioned. However, in this method, there was an option to reduce seismic forces estimating the fundamental period of vibration using a formula proposed in the Code; this reduction was possible mainly for long period structures on firm soil.

Modal dynamic analysis was specified for buildings taller that $60 \mathrm{~m}$, but it could be used for any height. Step by step dynamic analysis could also be used.

Design spectra for the three types of soil are shown in fig 3; they have different dominant periods of the soil. For soft soil, the characteristic periods are 0.8 and $3.3 \mathrm{sec}$, for transition soils, 0.5 and $2.0 \mathrm{sec}$ and for firm soils, 0.3 and $0.8 \mathrm{sec}$. For the region of the spectra between zero and the first characteristic period, the ductility reduction factor was reduced in terms of the period of the structure, considering that for very rigid structures the ductility is not fully developed.

Strength reduction factors and load factors in limit design were similar to the previous Code, as well as allowable stresses, but for steel structures the increment in allowable stresses was reduced from $50 \%$ to $33 \%$.

A few months before the 1985 earthquake, the 1976 Code was under revision; there was a tendency to lower the seismic coefficients, but the 8.1 magnitude event, with epicenter in Michoacan, that ocurred on september 19, 1985 , demonstrated that they should be increased.

Emergency modifications were published in the Official Diary on october 19, 1985, ref 6 . These modifications should be used for the reparation of damaged structured or for the structural design of new buildings, in the zones of soft or transition soils.

Among the more important modifications to the 1976 code there were: an increase in seismic coefficients to $0.40 \mathrm{~g}$ in the soft soil and to $0.27 \mathrm{~g}$ in transition soils.

For zero period, maximum accelerations of the soil were $0.10 \mathrm{~g}$ and $0.054 \mathrm{~g}$ instead $0.060 \mathrm{~g}$ and $0.045 \mathrm{~g}$ of the previous code. Comparing these values with those obtained in the response spectrum of the record at SCT during the 1985 event, it was found that they were not enough to cover the $1 \mathrm{~g}$ maximum ordinate corresponding to a period of $2 \mathrm{sec}$ and $5 \%$ of critical damping, fig 4 . It was considered that usual overstrength of structures, inelastic behavior and some other modifications in the strength calculations would suffice to have a safe design.

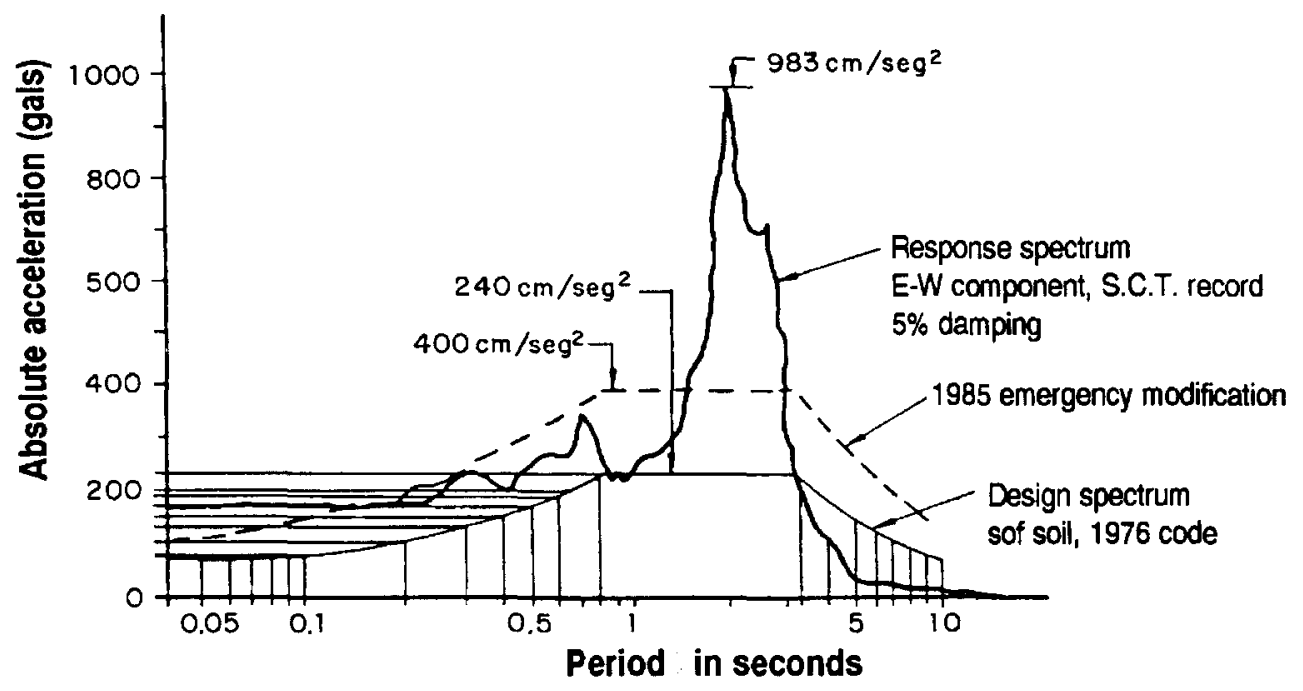

Fig. 4 Design and Response Spectra 
For computing strength of columns the resistance reduction factor was modified from 0.75 to 0.50 , when ductilities considered were larger than 2 . Also, minimum dimension of columns was $30 \mathrm{~cm}$; minimum live loads for office buildings were raised to $180 \mathrm{~kg} / \mathrm{m}^{2}$ instead of $90 \mathrm{~kg} / \mathrm{m}^{2}$; the ductility factor of 6 was eliminated, and the requirements to use a value of 4 were raised; additional restriccions were included for the design of steel and reinforced concrete structures.

A new ductility factor of 3 was permitted for the design of buildings with open web steel beams or flat slabs, but reducing the equivalent width of beams in this case.

Maximum eccentricity was restricted to $20 \%$ on the dimension of the plan of the building, for torsional considerations.

Friction piles were permitted but with reduced capacity; some requeriments were added concerning detailing to scale of connections between structural elements, inspection and supervision of jobs and other pertinent concepts.

On July 3, 1987 a new version of the Code was published in the Official Diary, modifying the Emergency Regulations of 1985, ref 7 .

In this Code, the current version, classification of structures according to its use was reduced to two groups, $\mathrm{A}$ and $B$, but this was subdivided in B1 and B2 depending on height, covered surface and type of soil.

Zonification was revised, and some parts of the soft or transition soil have more stringent requirements.

For the first time in the history of the Code, it was recognized the possibility of damage due to earthquake. With respect to architectural aspects, it was emphasized the convenience of a regular squeme in order to reduce seismic effects. Some recommendations concerning finishings and nonstructural elements were included.

A new Technical Complimentary Norm for Seismic Design was issued, ref 8, but the Code still has general recommendations concerning methods of analysis, combination of actions and seismic coefficients.

Seismic coefficients for Group B buildings are $0.40 \mathrm{~g}$ for the soft zone, $0.32 \mathrm{~g}$ for the transition zone and 0.16 $\mathrm{g}$ for the firm zone; this values should be multiplied by 1.5 for group $A$ buildings.

Characteristic periods of the soil were modified as follows: 0.6 and $3.9 \mathrm{sec}$ for soft soil, 0.3 and $1.5 \mathrm{sec}$ for transition soil and 0.2 and $0.6 \mathrm{sec}$ for firm soil. Design spectra are shown in fig. 5.

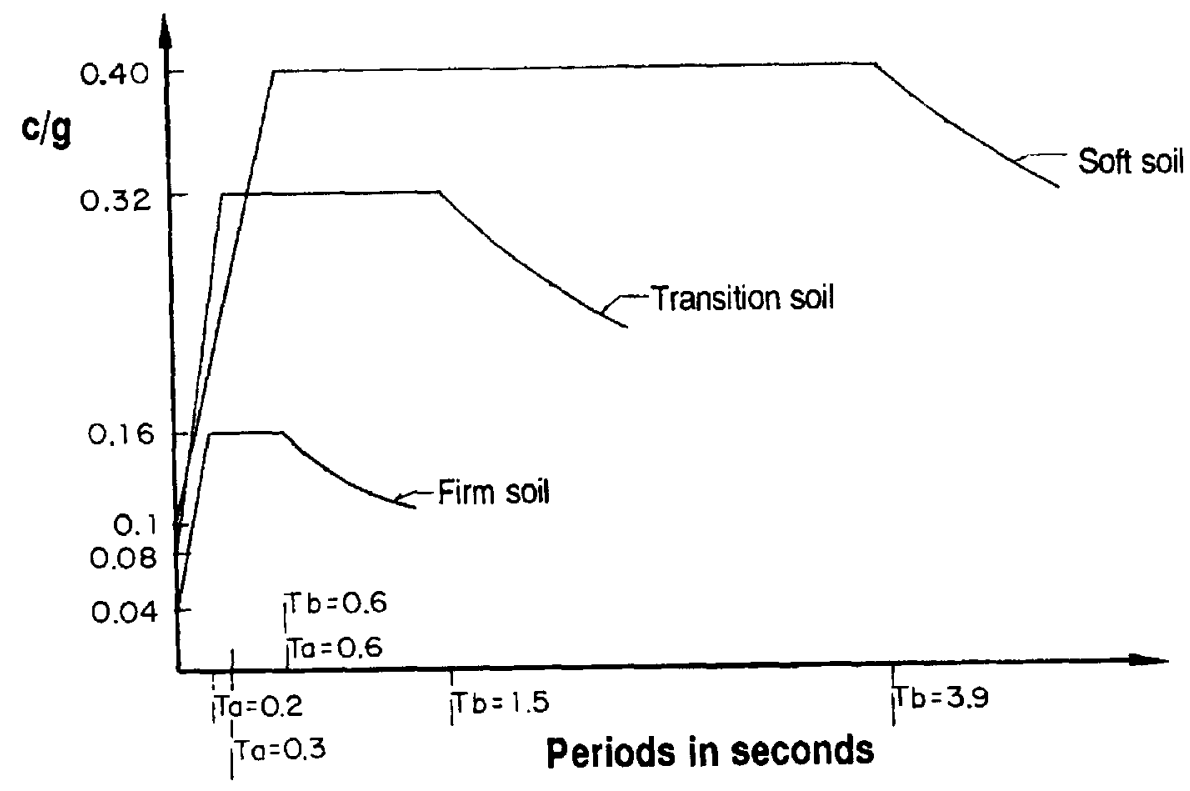

Fig. 5 Response Spectra 1987 Code 
Lateral allowable displacements were reduced to $0.006 \mathrm{~h}$, which can be increased to $0.012 \mathrm{~h}$ if there is not a possibility of damage to non-structural elements. For the soft soil zone, this requirement is more severe than strength considerations, as no reduction in forces is permitted in displacement calculations.

Separation between adjacent buildings was increased substancially to avoid pounding; for a height of $20 \mathrm{~m}$ (6 stories approximately) separation should be around 48 to $72 \mathrm{~cm}$ in soft soil zones and around 28 to $52 \mathrm{~cm}$ in firm soil zones.

If the height is $30 \mathrm{~m}$ (or 10 stories) separation should be around 72 to $108 \mathrm{~cm}$ in soft soil or 42 to $78 \mathrm{~cm}$ in firm soil.

A very important aspect of the 1987 Code in the case of group A or B-1 buildings is that besides a Responsible at the Job, a Corresponsible in stnictural safety is needed. This person has to have enough experience to check all the studies and projects as well as the materials and construction procedures to be sure that construction is made in accordance with the project.

The new Complementary Norms establish static and dynamic methods of analysis, earthquake design spectra, reduction factors that may be used in terms of expected ductility. It is also considered the possibility of external devices to absorb energy.

The reduction ductility factors $Q$ are 1, 1.5, 2, 3 or 4 . For the values of 3 or 4 special ductile moment frames should be used, either in structural steel or reinforced concrete. Each direction of analysis may have different values, depending on structural features, but $Q$ should be the lowest corresponding to the different levels of the building. If the structure is irregular, $Q$ should be reduced $20 \%$.

In the case of torsional computations it is required to locate a center of strenght; but it was demostrated that in practical cases its position is not well defined, ref 9 and this requirement will disappear.

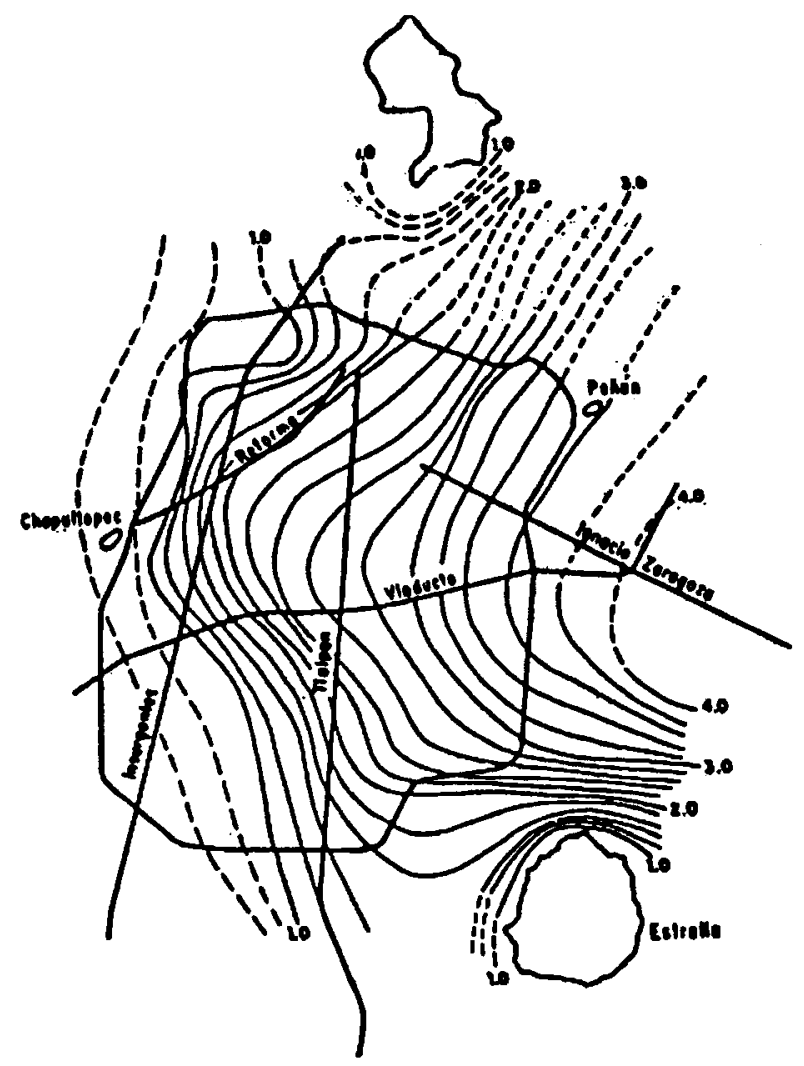

Fig. 6 Dominant Periods in Soft Soil, D.F. 
In an Appendix to the Norms, recommendations to take into account soil-structure interaction are given in order to modify the period of the structure when this is important. It also allows to modify the design spectrum for a given site if the characteristic periods of the soil motion are known; there is map of the city with values of these periods, based on microtremor measurements, which for the soft soil zone varies between 1 and $4 \mathrm{sec}$, depending on the thickness of the clay strata, fig. 6 .

Earthquake effects should be calculated for at least two orthogonal directions; these effects should be combined considering $100 \%$ of the effects in one direction simultaneous with $30 \%$ of those in the perpendicular direction.

Complimentary Norms for the design of reinforced concrete structures are similar to $\mathrm{ACI}$ recommendations but not equal; in some aspects they include results of local research. In this Code two types of concrete were established, the main difference between them is the weight and modulus of elasticity. For buildings of groups $A$ and B-1 the best quality should be used, it requires more control in aggregate selection and fabrication.

Masonry complimentary Norms are mainly based on research during several years on local materials.

Steel Complimentary Norms are very similar to AISC Specifications, using load factors and ultimate strenght design methods. Complimentary Norms for the Design of Foundations reflect the experience obtained in many years of dealing with the difficult subsoil of Mexico City.

The result of many research projects developed after the september 19,1985 earthquake have been incorporated in the code. Other results have been analized and may produce future modifications of the Code, which has been studied along these years.

(Note: on august 2, 1993 a new code was approved)

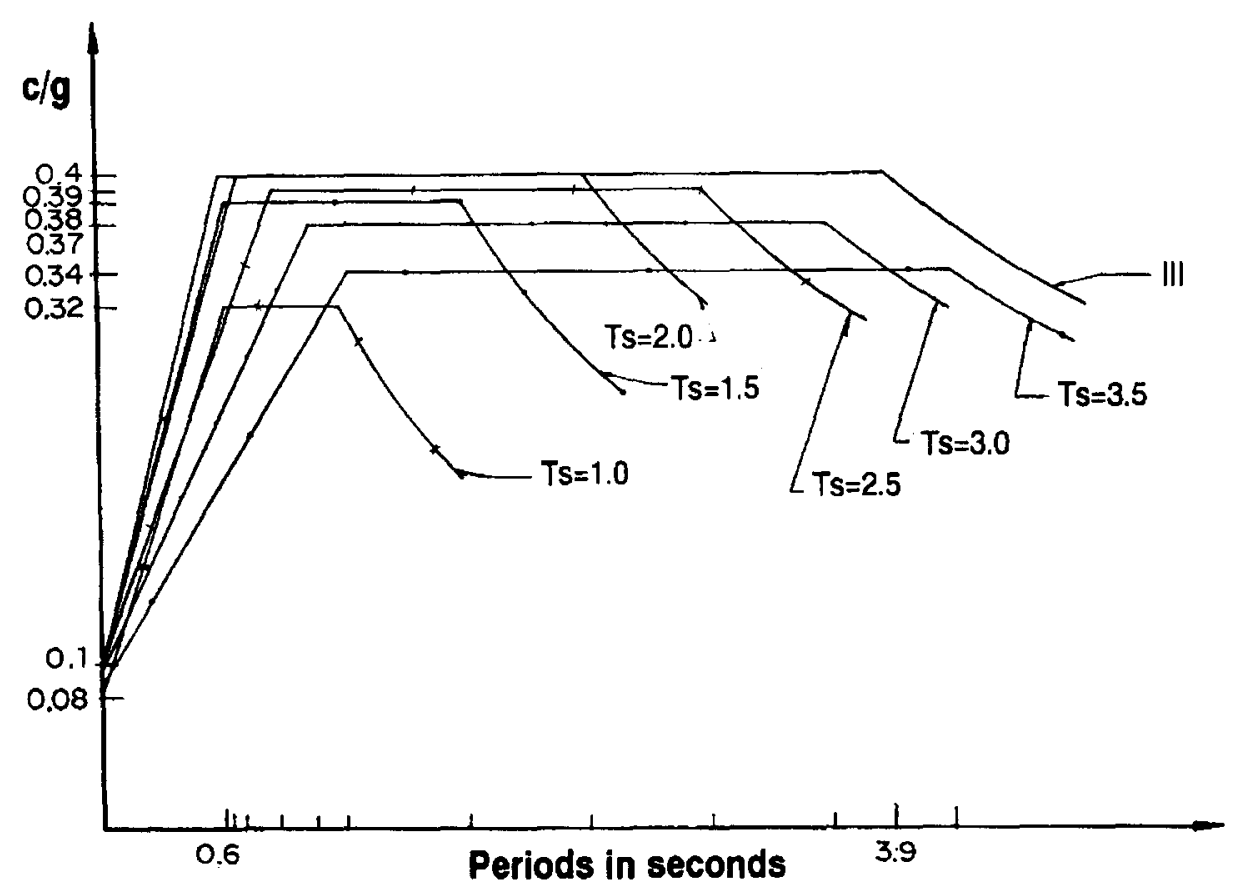

Fig. 7 Response Spectra, soft soil, for different characteristics, Ts periods, 1987 Code 


\section{SOME COMMENTS ABOUT THE 1987 CODE}

One of the main concerns about the code is related with design spectra for the soft soil, as a very flat spectrum is proposed due to lack of information, because very few records were obtained during the 1985 earthquake.

Soft soil layers filter vibrations coming from the epicenter and modify the records considerably, compared with those obtained on firm soil; there is a tendency to have nearly harmonic motions with periods of vibration igual to the dominant period at each site, which produce response spectra of narrow band, with marked peaks at the dominant period. Therefore, if the soil periods vary as shown in fig 6, response spectra would have peaks at each dominant period and the design spectra for that site would not be as flat as the proposed one, which is an envelope of different sites.

This gives structural engineers a false sensation that the response of structures is independent of the period of vibration of the soil at each site.

Using the criteria of the Appendix of the Norms to propose design spectra for each site as a function of its characteristic period of vibration, a series of design spectra can be obtained as shown in fig 7 .

After the 1985 earthquake more than one hundred strong motion accelerometers were installed in different places of the city. In April 1989 a moderate earthquake produced valuable information to define in a better way the curves shown in fig 6; so, in the future, with more records, it will be possible to propose different design spectra according to the information produced by these accelerometers.

Another point related with the design spectra is its maximum acceleration, which was set as $0.4 \mathrm{~g}$. It is recognized that the SCT record did not correspond to the strongest motion of the soil in 1985 , as the destruction some kilometers to the north was larger that at SCT. It is also accepted that the 1985 event is not necessarily the strongest that may affect the City. In fact the epicenter of this motion was nearly $400 \mathrm{~km}$ away from the City and there are other possible epicenters which may develop similar magnitude events, but closer to the City.

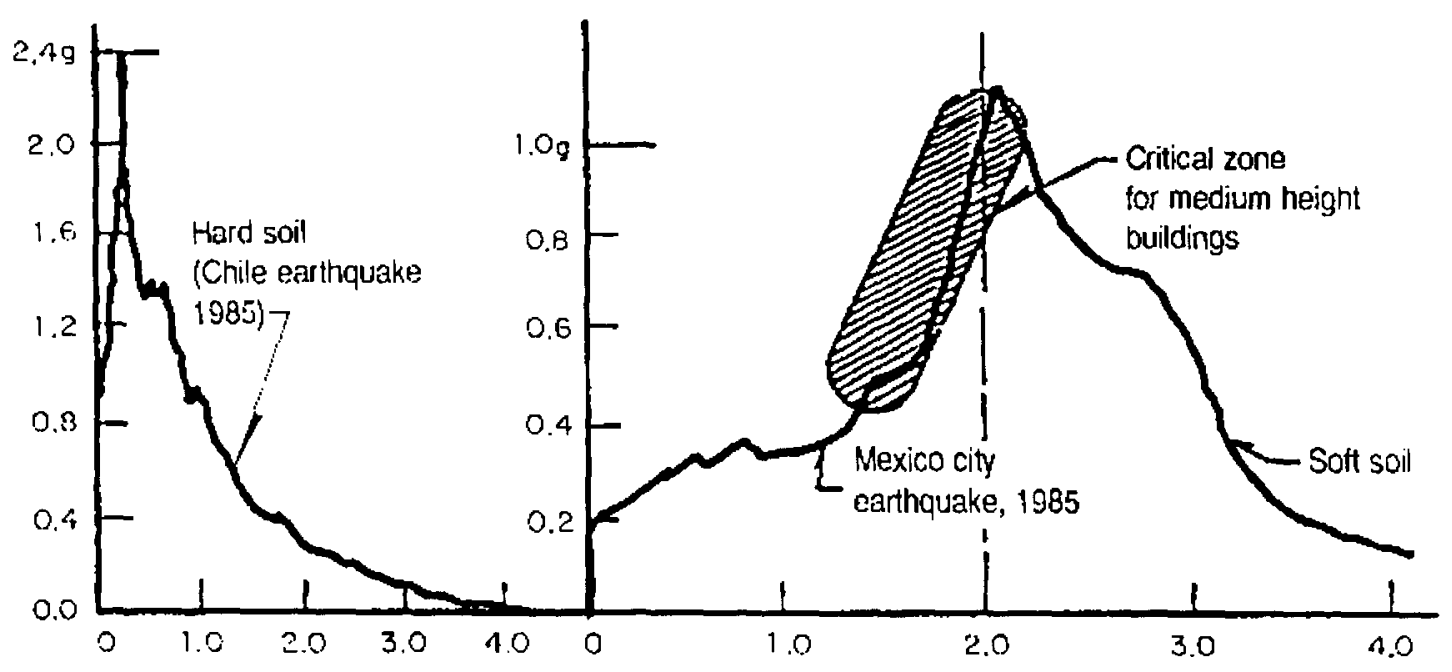

Fig. 8 Typical Response Spectra for hard or soft soil for $5 \%$ damping and elastic behaviour 
Analyzing historical earthquakes it was found that the Valley of Mexico has been shaken by at least 50 strong earthquakes in the past, with around 8 events similar or bigger than the 1985 earthquake. It appears that in April 1845 a strong earthquake, originated in Guerrero may have produced larger accelerations in the soft soil zones of the Valley. Therefore, if this motion is repeated in the future it may produce a lot of damage again.

The $0.4 \mathrm{~g}$ acceleration was obtained analyzing $2 \mathrm{sec}$ period single degree structures, with $5 \%$ critical damping and elasto-plastic behavior. This is not the actual form in which a real multiple degree of freedom structure behaves in a step by step analysis; therefore, it is possible to have larger damage than expected in the case of structures having fundamental periods of vibration relatively close to the dominant period of the soil motion due to resonance effects, especially if the period increases by the formation of several plastic hinges and the response is large, as shown in fig 8 .

Ductility reduction criteria is best suited for descending zones of the response spectrum as in the case of firm soil or for very long period structures on soft soil, as indicated in fig 8 , but it may be very dangerous for long strong earthquakes if the structure falls in the ascending branch of the peak of the spectrum.

\section{REFERENCES}

1. "Reglamento de las Construcciones y de los Servicios Urbanos en el Distrito Federal" en Diario Oficial, 23 de Julio de 1942.

2. "Modificaciones al Reglamento de las Construcciones y de los Servicios Urbanos en el Distrito Federal para Prevenir los Efectos de los Sismos" en Diario Oficial, 18 de Septiembre de 1957.

3.- "Reglamento de Construcciones para el Distrito Federal. Cap. XXXI, Diseño por sismo" en Diario Oficial, 9 de Febrero de 1966.

4. "Reglamento de Construcciones para el Distrito Federal. Titulo IV. Requisitos de Seguridad y de Servicio para las Estructuras" en Diario Oficial, 14 de Diciembre de 1976.

5. "Some Lessons From the March 14, 1979 Earthquake in Mexico City", E. del Valle, Proceedings 7th World Conference on Earthquake Engineering, vol. 4, Istambul, Turkey, 1980.

6. "Modificaciones de Emergencia al Reglamento de Construcciones para el Distrito Federal" en Diario Oficial, 18 de Octubre de 1985.

7. "Reglamento de Construcciones para el Distrito Federal" en Diario Oficial, 3 de Julio de 1987.

8. "Normas Técnicas Complementarias para el Diseño por Sismo" en Gaceta Oficial del Departamento del Distrito Federal, 5 de Noviembre de 1987.

9. Comentarios al Inciso 8.6 de las Normas Técnicas Complementarias para el Diseño por Sismo, J. Damy, Revista Ingenieria Sísmica, No. 33, Soc. Mex. de Ing. Sísmica, A.C., Agosto, 1988.

10. "Reglamento de Construcciones para el Distrito Federal en Diario Oficial", 2 de agosto de 1993. 